\title{
Evaluation of Traditional Container Glass Recycling Systems against Selected Environmental Impact Criteria Using the LCA Method
}

\author{
Bartosz Zegardło ${ }^{1 *}$, Katarzyna Drużba ${ }^{1}$ \\ 1 Siedlce University of Natural Sciences and Humanities, Research Team of Quantitative Methods and Spatial \\ Management, ul. B. Prusa 14, 08-110 Siedlce, Poland \\ * Corresponding author's e-mail: bart.z@wp.pl
}

\begin{abstract}
The research results presented in this article are an answer to the controversial theses questioning the validity of traditional recycling methods. The voices of scientific circles which have appeared recently indicate that irrational waste management and energy-intensive recycling of selected products bring more harm than benefits to the environment. This paper is devoted to the assessment of selected environmental effects of traditional recycling processes for container glass. The environmental impact of collection, segregation, transport and remelting of glass waste was analysed using the LCA (Life Cycle Assessment) method and available databases. The environmental impact of the processes described was assessed in terms of selected criteria: climate change, energy depletion, air emissions, toxicity and depletion of natural resources. Two methods were used for the calculations: the method of the Institute of Environmental Engineering of Leiden University-CML and the Ecological Scarcity Method (ESM). The calculations were carried out for an exemplary city located in eastern Poland. The study showed that, compared with purely natural glass production, the production of recyclates was more favourable in terms of all the above-mentioned factors. Additional calculations made it possible to estimate the waste transport distance, for which the environmental impact of transporting recyclate to the glassworks made the glass recycling process by re-melting less favourable than the production of packaging from natural resources.
\end{abstract}

Keywords: packaging glass, glass recycling, life cycle assessment, environmental impact

\section{INTRODUCTION}

There is a growing trend in scientific circles to question the validity of traditional ways of recycling various materials. In some cases, recycling can be a source of toxic emissions, such as heavy metals [Ahirwar, Tripathi, 2021]. A careful observation of the environmental impact of the processes, e.g. adaptation of wastes, to which they are subjected in the recycling processes, proves that they are often detrimental to the environment. Recovery of some materials can be difficult and costly, whereas transport is not very profitable [Zegardło et al. 2018]. Washing the waste consumes valuable water resources. The use of detergents in these processes leads to the introduction of chemicals into the environment, which must be neutralised. The transport and segregation of waste consume energy resources in the form of fuels, while causing the introduction of toxic gases into the environment. A very thorough analysis of these issues shows that traditional recycling methods are not always the optimal solution from an environmental point of view.

There is some controversy about the traditional recycling of packaging glass materials. Packaging glass is silicon-soda-lime glass made from sand, limestone and soda, used for storage and transportation of various products [Borkowski, Ingaldi, Jagusiak-Kocik, 2014]. Glass packaging is usually transparent, but increasingly, small amounts of oxides such as chromium, cobalt, selenium or nickel are added to its composition to give it colour [Franco, Falqué, 2016]. The quality of glass packaging is nowadays very high and glass is characterised by such features as: chemical inertness, no harmful effect on the substance stored in them, chemical resistance to 
the atmosphere, water, acids and bases, and impermeability to odours, gases, liquids and water vapour [Nawara et al., 2017]. Packaging glass can be formed into different shapes and coloured in a variety of colours. Examples of glass packaging can be jars, bottles or glass packaging for cosmetics.

Traditional glass recycling consists of several steps. The first process is the collection of waste glass, where glass is separated into types and colours to ensure the correct chemical composition for the intended use [Harrison, Berenjian, Seifan, 2020]. Next, to ensure good cullet quality, any impurities and foreign bodies such as ceramics, steel or non-ferrous metals must be removed from the glass [Kusnier, 2010]. The next stage is glass grinding, which is the processing of waste glass into cullet [Dhiri et al., 2018]. The crushed glass is mixed with other raw materials and melted in a furnace at a temperature of more than $1000^{\circ} \mathrm{C}$, thus transforming the raw materials into glass mass and bringing it to a temperature that meets the requirements of moulding.

The environmental impact aspects of glass recycling have already been addressed in the literature. The article [Wong et al., 2020] described a study in which recycled plastics, waste glass and concrete were mixed to create concrete pavements. The article [Nasier, 2021] indicated the use of waste materials, including glass, as aggregates for concrete production. Other researchers, in the article [Silva et al., 2021] demonstrated that glass waste has great potential to be used as a raw material for foam glass panels. Gebremariam et al. [Gebremariam et al., 2021] argued that sustainable concrete should be created from waste materials, including recycled glass, to reduce the consumption of natural resources. The article [Ting, Tay, Tan, 2021] investigated the effect of recycled cullet as a replacement for sand in 3D printing. Researchers in the article [Lu et al., 2020] demonstrated that the use of waste glass cullet and other recycled fine aggregates in cement mortar production has a positive impact on the environment. In order to reduce the consumption of a large amount of natural resources, the article [Chen et al., 2020] indicated that one way to recycle glass products can be to mix it with cement as an aggregate or filler.

Taking into account the divergent results of the studies presented above and the ambiguous assessment of environmental losses and benefits, the study presented in this paper cites the values of selected environmental effects caused by traditional processes of packaging glass recycling estimated for a medium-sized town located in eastern Poland. The environmental impact of collection, segregation, transport and remelting of glass waste was analysed using the LCA (Life Cycle Assessment) method and available databases. The environmental impact of the processes described was assessed in terms of selected criteria: climate change, energy resource depletion, air emissions, toxicity and depletion of natural resources. Conclusions were drawn from the presented results, which can be used in industrial activities.

\section{RESEARCH METHODOLOGY}

According to [Kowalski, Kulczycka, Góralczyk, 2007] the LCA (life cycle assesment) method is a research system in which the influence of various processes on the natural environment is assessed. The aim of this method is to detect and indicate the threats that may occur in the environment. Its main idea is to determine the final result for the investigated process, as well as to estimate and evaluate its consequences for different criteria of risks in the environment. The research is carried out according to a unified procedure, which is defined by the following standards: [EN ISO 14040, 14041, 14042, 14043]. The ISO 14040 standard specifies the methodology of environmental impact assessment, in which four stages of research are distinguished. At the beginning, there is the definition of the purpose and scope of activities, where the basis of research is indicated. The second phase is the dataset analysis (LCI), where the materials consumed and the resulting emissions or wastes that burden the environment are identified. The third phase, the impact assessment phase, identifies the potential environmental impacts. The final phase is the interpretation phase, where the information from the results is evaluated [ISO 14040: 2006].

In this study, the openLCA 1.10.3. computer software, which is open source, was used for the research and analysis. Its main purpose is life cycle assessment and supporting sustainable development. It provides the publicly accessible databases with the information on various processes. These are continuously updated and shared by system users. In addition, the software provides 
detailed information on the results of calculations and analyses, as well as the possibility to import and export data and easily share models.

On the basis of the guidelines described in the standards, the context of the study was clarified in the first stage of work, in the aim and scope phase. The environmental implications were conducted for a sample town located in eastern Poland with a population of approximately 70,000 . This location functioned as a waste generation site in the calculations. It was agreed that the aim of the analyses would be to compare the environmental effects of the production of glass packaging materials. The first study was carried out for the production of glass packaging materials in a traditional manner, i.e. by drawing substrates from natural resources. It was designated with the glassNAT symbol. In the second study (glassREC), it was assumed that the production of packaging materials would only take place on the basis of recyclates. Waste, on the other hand, will be obtained by sorting and storing at selective waste collection points. From there, they will be transported to smelters where they will be melted down. The survey assumed that the location of glass melting workshops is $148 \mathrm{~km}$ away from the place of waste generation. The functional unit used for the calculations was one tonne of glass packaging. In addition, a study was carried out under the name glassTRANS, which consisted in writing a formula in Excel to estimate the environmental impact of all the parameters investigated by successively increasing the distance of glass transport to the glassworks.
The second phase of the project was the analysis of the dataset, which determined the raw materials that enter the system as well as identified the emissions and waste that enter the environment. The databases used in this phase were ef_secondarydata_201908_1 and ELCD_3_2 greendelta_v2_18_1. These have identified all the raw materials, including those used as fuels and the depreciation of equipment required both for the extraction of natural aggregates and for the transport and adjustment of waste.

The third phase of the study was impact assessment. At this stage of the work, calculations of the values of the effects of the studied processes on the environment were performed using two methods depending on the given element of influence. One of the methods used was the method of the Institute of Environmental Engineering of the University of Leiden-CML, which was evaluated for three parameters. In this way, the impact on climate change was examined, which was expressed in kilograms of $\mathrm{CO}_{2}$ equivalent released into the environment. The depletion of energy resources expressed in units of MJ and human toxicity expressed in units of $\mathrm{kg}$ of 1,4-dihlorobenzene equivalent were also assessed using this method. Another method used in the study was the Ecological Scarcity Method (ESM), which examined two parameters. The first parameter was depletion of natural resources and the second was total air emissions. Both parameters were expressed in units of UBP, or units of ecological scarcity.

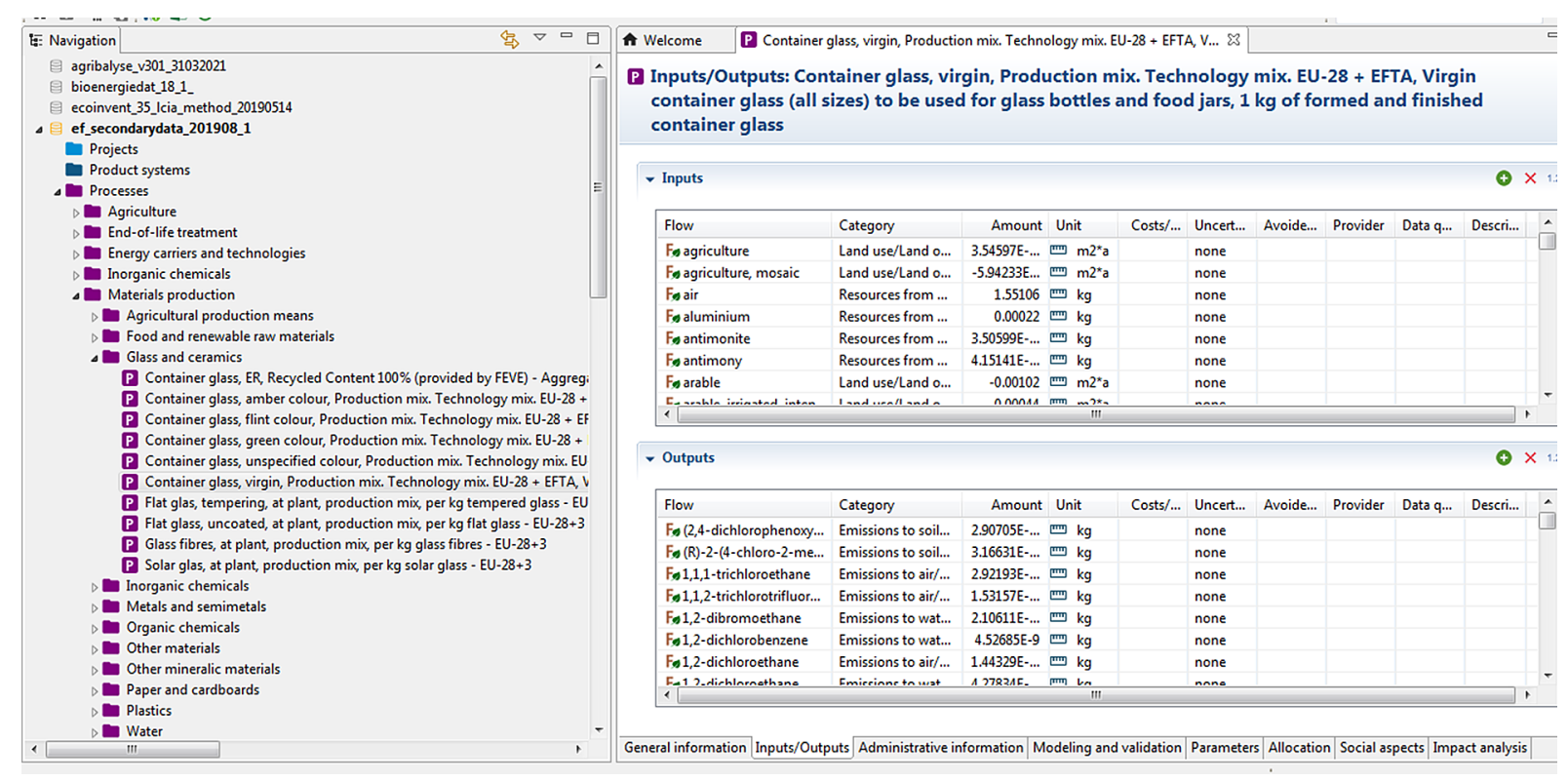

Photo 1. Screenshot of the monitor with some of the input data included. 
The final phase of the research was the interpretation phase. In this phase of the research work, the information from the results was compared and analysed.

\section{RESEARCH FINDINGS}

The results of the research analyses are summarised in Table 1 and Figure 1.

The research work carried out shows that the production of glass packaging materials on the basis of recyclates for the adopted allocation unequivocally brings more environmental benefits than their production in a traditional way, drawing substrates from natural resources. All the parameters studied were higher for the production of glass packaging in the traditional way. The parameter of influence on climate change expressed in kilograms of ${ }_{\mathrm{CO} 2}$ equivalent introduced to the environment was $65 \%$ higher in the case of manufacturing glass packagings in a traditional way, than in the case of manufacturing them with the use of recyclates. Another parameter assessed, i.e. the amount of energy resource depletion expressed in MJ units, was also 64\% higher in the case of production of glass packaging from natural resource substrates, in comparison with the production of glass packaging from waste materials. In the case of human toxicity expressed in units of $\mathrm{kg}$ of 1,4-dihlorobenzene equivalent, the value of conventional glass packaging production was also $67 \%$ higher than that of production from reyclates. Another parameter, depletion of natural resources expressed in UBP units, i.e. units of ecological scarcity, indicated a similar value. Here, it was assessed that the value of manufacturing packaging from the substrates originating from natural resources was $67 \%$ higher than for manufacturing glass packaging from recyclates. The last parameter assessed was the total emission of pollutants into the air expressed in UBP.
Here, similarly, the value of manufacturing glass packaging in the traditional manner was $67 \%$ higher compared to manufacturing it from waste materials.

An additional study, carried out under the name glassTRANS, concluded that it was only at a transport distance of $4,745 \mathrm{~km}$ that the climate change impact expressed in kilograms of $\mathrm{CO}_{2}$ equivalent released into the environment was higher for glass production in the recycling system. Similarly, at this distance of transport of recyclate, the parameter of energy depletion expressed in MJ exceeded by $15 \%$ the value calculated for glass production from natural resources. It is also worth noting that despite the significant impact of transport at this distance, such parameters as human toxicity, depletion of natural resources and emissions of harmful compounds into the air were still lower for glass production from waste materials. The human toxicity value, which was expressed in units of $\mathrm{kg}$ of 1,4-dihlorobenzene equivalent, was 55\% lower for glassTRANS compared to conventional glass packaging production. At this recyclate transport distance, the parameter - depletion of natural resources expressed in units of UBP i.e. units of ecological scarcity was also $66 \%$ lower in comparison with glass packaging production from natural resource substrates. Similarly, in the case of the last parameter, which was the total emission of pollutants into the air expressed in UBP, this value was also $64 \%$ lower in the glassTRANS study, than in the case of manufacturing packaging in a traditional manner.

The research results obtained show that the production of glass packaging on the basis of recyclates is definitely much more beneficial for the environment than the use of a traditional production method, i.e. drawing substrates from natural resources. All the parameters studied were lower for the production of glass packaging from waste materials.

Table 1. Summary of test results

\begin{tabular}{|c|c|c|c|c|c|c|}
\hline Lp. & Method used & Value & Unit & glassNAT & glassREC & glassTRANS \\
\hline 1 & $\mathrm{CML}$ & $\begin{array}{c}\text { Climate change } \\
\text { GWP 100 }\end{array}$ & $\mathrm{kg} \mathrm{CO}_{2}$ eq. & 0,96528 & 0,33799 & 0,96681 \\
\hline 2 & $\mathrm{CML}$ & $\begin{array}{c}\text { Depletion of } \\
\text { resources }\end{array}$ & $\mathrm{MJ}$ & 10,67842 & 3,79642 & 12,55793 \\
\hline 3 & $\mathrm{CML}$ & Human toxicity & $\begin{array}{c}1,4-\text { dihlorobenzene } \\
\text { eq. }\end{array}$ & 0,19378 & 0,06462 & 0,08710 \\
\hline 4 & $\mathrm{ESM}$ & Natural resources & UBP & 1,46081 & 0,48201 & 0,49157 \\
\hline 5 & $\mathrm{ESM}$ & Emission to air & UBP & 2171,67517 & 718,50656 & 781,70901 \\
\hline
\end{tabular}


a)

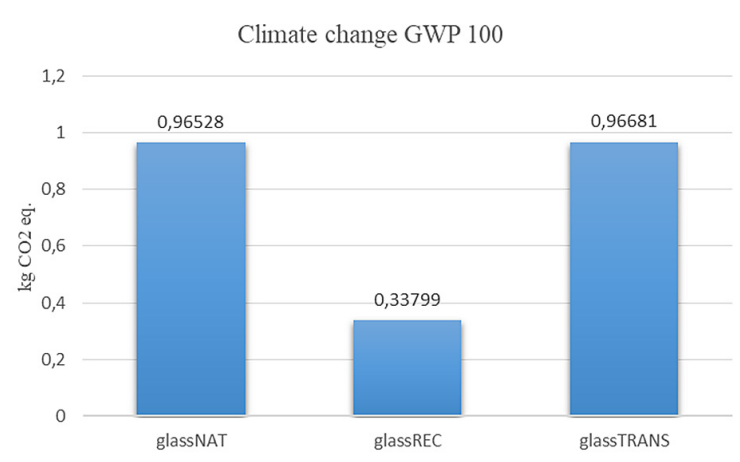

c)

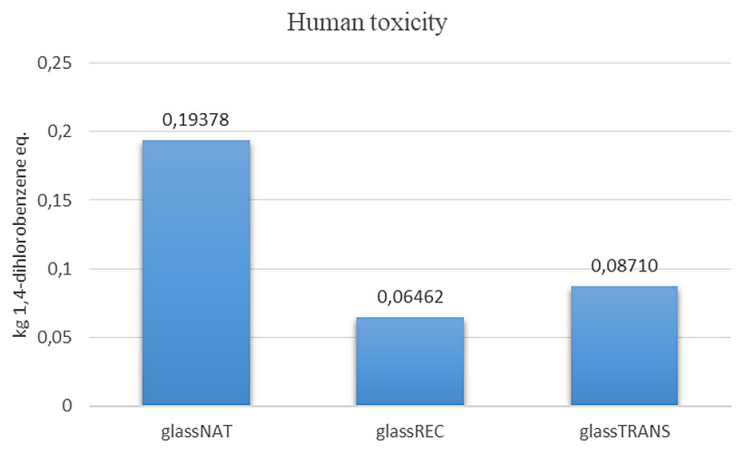

b)

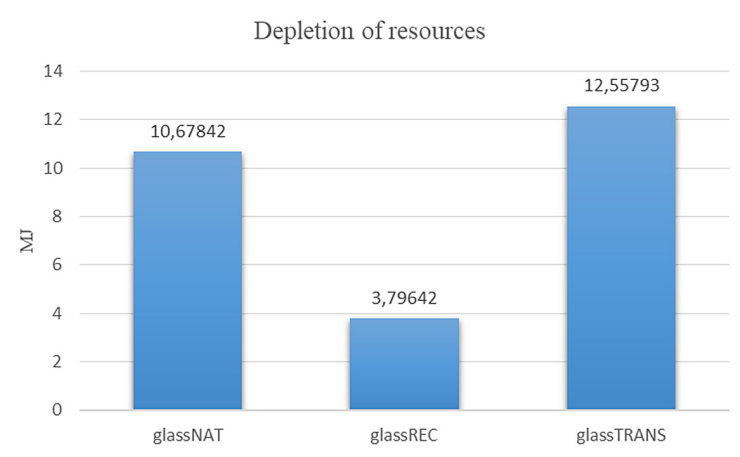

d)

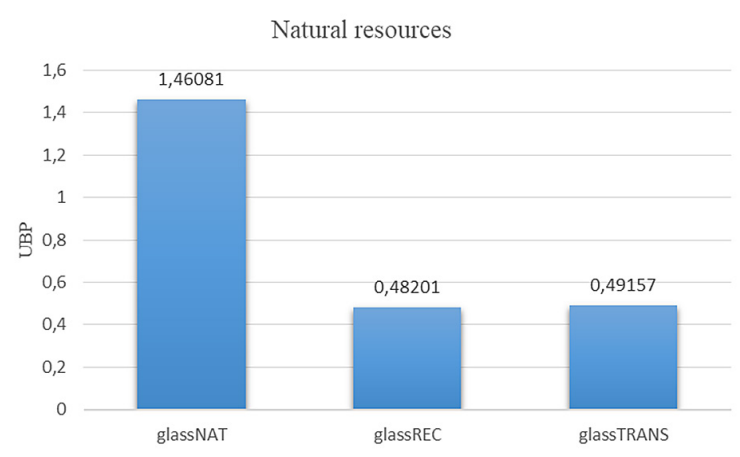

e)

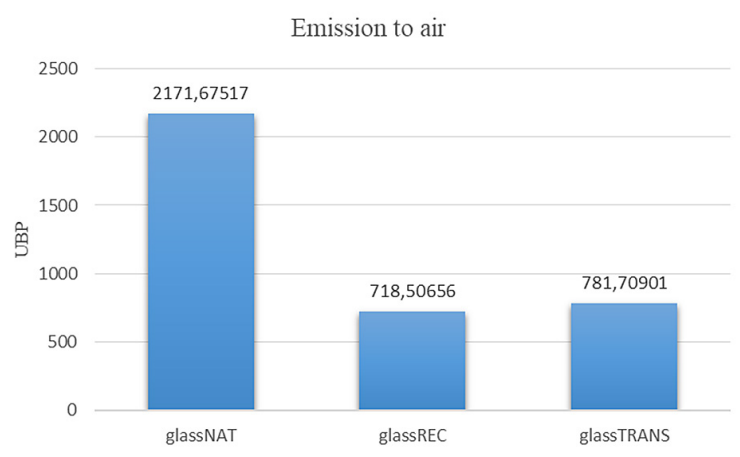

Figure 1. Comparison of test results for subsequent parameters

The results of the additional study show that even despite the long transport distance of $4745 \mathrm{~km}$, such parameters as human toxicity, depletion of natural resources and air emissions are still lower for glass production from waste materials compared to glass packaging production from substrates derived from natural resources. It was only with such a long transport distance that the climate change impact parameter was higher for glass production in the recycling system. In this case, the parameter for the magnitude of the depletion of energy resources was also higher for recycled-based glass packaging production.

\section{CONCLUSIONS}

The results presented, it may be stated that collection, segregation, transport and re-melting of glass waste are worth recommending and should be implemented in industrial systems. It positively influences the environment. Owing to such activities in the production of glass packaging, it is possible to reduce the amount of substrate obtained from natural resources as well as to reduce environmental pollution and landscape degradation. By using glass recycling, it is also possible to reduce the amount of waste in landfills. 


\section{REFERENCES}

1. Ahirwar R., Tripathi A.K. 2015. E-waste management: A review of recycling process, environmental and occupational health hazards, and potential solutions, Environmental Nanotechnology, Monitoring \& Management, 15, 100409.

2. Borkowski S., Ingaldi M., Jagusiak-Kocik M. 2014. Nonconformity structure and importance of visual inspection types during glass packaging production, Support Systems in Production Engineering, 2014, 3(9), 43-51.

3. Chen B. et al. 2020. Study on the fire resistance performance of cementitious composites containing recycled glass cullets (RGCs), Construction and Building Materials, 242, 117992.

4. Dhir Obe R.K. et al. 2018. Sustainable Construction Materials. Glass Cullet, Woodhead Publishing Series in Civil and Structural Engineering, 35-96.

5. Environmental Management-Life Cycle Assessment-Principles and Framework; ISO 14040, 2006. ISO: International Organization for Standardization Geneva, Switzerland.

6. Franco I., Falqué E. 2016. Glass Packaging Developments - An Historical and Future Perspective, Reference Module in Food Science.

7. Gebremariam A.T. et al. 2021. Comprehensive study on the most sustainable concrete design made of recycled concrete, glass and mineral wool from C\&D wastes, Construction and Building Materials, 273, 121697.

8. Harrison E., Berenjian A., Seifan M. 2020. Recycling of waste glass as aggregate in cement-based materials, Environmental Science and Ecotechnology, 4, 100064.

9. Kowalski Z., Kulczycka J., Góralczyk M. 2007. Ekologiczna ocena cyklu życia procesów wytwórczych (LCA), Wydawnictwo Naukowe PWN, Warszawa.

10. Kuśnierz A. 2010. Recycling of glass, Prace Instytutu Ceramiki i Materiałów Budowlanych, 3(6), 22-33.

11. Lu J.-X. et al. 2020. Synergetic recycling of waste glass and recycled aggregates in cement mortars:
Physical, durability and microstructure performance, Cement and Concrete Composites, 113, 103632.

12. Nasier S. 2021. Utilization of recycled form of concrete. E-wastes, glass, quarry rock dust and waste marble powder as reliable construction materials, materialstoday: Proceedings.

13. Nawara P. et al. 2017. Photometric analysis of the structure of selected types of packaging used in the processing and cosmetics industry. Electrotechnical Review, 12, 119-122.

14. Pikoń K., Gatnar M. 2009. Environmental nuisance of glass recycling. Archives of Waste Management and Environmental Protection, 11(1), 1-20.

15. PN-EN ISO 14040. Environmental managementLife cycle assessment - Principles and Structure, PKN, Warszawa 2000.

16. PN-EN ISO 14041. Environmental managementLife cycle assessment - Objective and scope definition and set analysis. PKN, Warszawa 2000.

17. PN-EN ISO 14042. Environmental managementLife cycle assessment - Life cycle impact assessment. PKN, Warszawa 2000.

18. PN-EN ISO 14043. Environmental managementLife cycle assessment - Life cycle interpretation. PKN, Warszawa 2000.

19. Silva R.C. et al. 2021. Recycling of glass waste into foam glass boards: A comparison of cradle-togate life cycles of boards with different foaming agents. Science of The Total Environment, 2021, $771,145276$.

20. Ting G.H.A., Tay Y.W.D., Tan M.J. 2021. Experimental measurement on the effects of recycled glass cullets as aggregates for construction 3D printing. Journal of Cleaner Production, 300, 126919.

21. Wong Y.C. et al. 2020. Field study on concrete footpath with recycled plastic and crushed glass as filler materials. Construction and Building Materials, 243, 118277.

22. Zegardło B., Drzymała T., Nitychoruk J., Jaworska B. 2018. Preliminary assessment of the possibility of using glass waste from exploited fluorescent lamps as aggregate for cement concrete. Autobusy - Technika, Eksploatacja, Systemy Transportowe, 19(6), 314-317. 